\title{
The Application of Simple Controlled Pressure Drilling Technology in Yingxi Block
}

\author{
ZHANG Guohui, Hugui ${ }^{1}$, CHEN rong ${ }^{1}$, LIU Xinyun, ZHANG Xiwen ${ }^{1}$ \\ ${ }^{1}$ PetroChina Research Institute of Petroleum Exploration \& Development, Beijing 100083, China
}

\begin{abstract}
Under the reservoir for exploration and development of Yingxi block in Qinghai oilfield, the chaigou formation is oil and gas reservoir complicated by the fault, and the exploration has been carried out over the years. The reservoir is a fracture - matrix pore dual medium type, with strong heterogeneity, fracture development degree, porosity and permeability variation range. The reservoir is very sensitive to wellbore pressure, the safety drilling density window is narrow, the conventional drilling leakage is frequent, the reservoir protection effect is poor, and the mechanical drilling rate is low. In 2016 six wells were selected for easy control and pressure drilling in the lower $\mathrm{E}^{2}{ }_{3}$ formation. The technology experiment has obtained good application effect, which provides successful experience to solve the complex and improve the engineering quality and benefit.
\end{abstract}

\section{Preface}

In recent years, Qinghai oilfield company has been drilling, logging and logging in accordance with Yingxi block. In-depth research three pressure profile prediction has achieved great results. A number of high-yielding wells were drilled.

In order to realize the purpose of optimizing the drilling and reducing the efficiency, Under Qinghai oilfield company pushed, the major drilling companies and research institutes had strengthened the Yingxi block. The research on the supporting process technology of the deep drilling were integrated, such as reducing the hole, salt drilling fluid system, "four in one" drill assembly and other supporting technologies. The integrated application had achieved the goal of reducing the efficiency. To achieve timely discovery and protect the oil and gas layer, raise the single well production. six wells were selected for easy control and pressure drilling in the lower $\mathrm{E}_{2}{ }^{3}$ formation..

\section{Difficulties in drilling construction of Yingxi block chaigou formation $\left(E^{2}{ }^{2}\right)$}

Aiming at the exploration and development ideas centered on "reducing the efficiency and efficiency", the Yingxi block drilling problems had been solved by practice and scientific research in recent years. Including changed borehole size $444.5 \mathrm{~mm} / 311.2 \mathrm{~mm} / 215.9$ $\mathrm{mm}$ to $311.1 \mathrm{~mm} / 215.9 \mathrm{~mm} / 152.4 \mathrm{~mm}$, the drilling time is greatly reduced and the casing cost was saved. The drilling fluid system, such as the undersaturated polysulfonate drilling fluid system guaranted the drill bit. The long salt mudstone, salt rock, paste mudstone strata, reduce the engineering complexity. Bit + single bend screw + MWD + centralizer + drill collar "four in one" drilling tool group improved drilling speed. The problem of anticlinal correction of large angle formation was solved, the quality of the well was guaranteed. In addition, conventional drilling technique is used to drill the chaigou formation under the main purpose reservoir. Now the two drilling problems are:

\subsection{Reservoir protection is difficult.}

The reservoir belongs to fracture-matrix pore dual medium type, which is complicated by fault. The fault block reservoir has strong heterogeneity, fracture development and porosity. The extent of gap and permeability variation is large, which affects the damage degree of reservoir during drilling. The engineering factors are very sensitive.

\subsubsection{Differential pressure}

Differential pressure is one of the main factors causing reservoir damage. With the filtrate of constant drilling fluid increases the pressure difference increases, the drilling fluid filtrate comes in. The depth of the reservoir and the severity of the reservoir damage are increased by the pressure difference.

\subsubsection{Soak time}

When the reservoir is open, the drilling fluid solid phase or filtrate come in. Under positive pressure difference, the drilling fluid enters the reservoir, its entering quantity and depth damage the reservoir. The longer the damage, the greater the damage. 


\subsubsection{Drilling fluid performance}

The performance of drilling fluid is closely related to reservoir damage. The depth and damage degree related to the solid phase and liquid phase of drilling fluid enter into the reservoir.

Using conventional drilling technology, the more the filtrate of drilling fluid under positive pressure and the larger the HTHP volume, the situation will become more worse.

Once the solid particles enter the reservoir pores and cracks, they can cause blockages in the permeable areas. The rate of the decrease will affect oil and gas discovery and production. The non-compatibility of drilling fluid filtrate and reservoir rock can induce water sensitivity, salt sensitivity and alkali sensitivity, it will cause the potential damage of the reservoir such as wetting reversal, surface adsorption. The incompatibility of fluid can induce the inorganic salt precipitation, water lock and emulsification of reservoir oil and gas channel. What is more noteworthy is that after years of drilling confirmed, the lower dry chaigou formation pressure is very close to the leakage pressure. When drilling into the fracture zone, under positive pressure, there is a large amount of drilling fluid entering the fracture, and the reservoir damage is large.

\subsection{Well control risk}

The fault development in the block resulted in the reservoir formation pressure and fracture-matrix pore. The gap development degree is wide, and even if there are adjacent wells no rules for the design of drilling fluid density, and the formation pressure and leakage pressure are connected. Fracture-matrix porosity, formation pressure and leakage pressure are interrelated in block development. The degree of fracture development is wider and the risk of loss of drilling fluid density is greater.

The safety drilling fluid density window is narrow, the drilling gas layer is prone to leak, overflow and leakage occur frequently.

Using conventional drilling techniques, the bottom positive pressure difference often exacerbates the leakage of drilling fluid, resulting in a rapid drop of the wellbore pressure. The flow of oil and natural gas into the wellbore can bring huge blowout risks to the operation of sealing and pressing well..

\subsection{Low penetration}

In recent years, the data of drilling completion of the chaigou formation in Yingxi block were investigated. It is known that conventional drilling machine has low drilling speed,the highest drilling speed is $2.67 \mathrm{~m} / \mathrm{h}$ and the lowest drilling speed is only $0.79 \mathrm{~m} / \mathrm{h}$, the average is $1.78 \mathrm{~m} / \mathrm{h}$. It is necessary to further explore the supporting technology of drilling speed.

\subsection{Non-production aging is high.}

In 2015, Qinghai oilfield company deployed 9 wells in Yingxi Block. The average completion period was 104 days, the cumulative production time was 743 days, proportion79. 59\%, cumulative non-production time 190 days. The single well leakage complex treatment accumulates 129 days, proportion $13.87 \%$.Especially, in the chugou formation, leakage accidents occur frequently.

\section{Control mechanism of simple controlled pressure drilling.}

The simple control pressure drilling technology is based on the fine control pressure drilling technology.On the basis of simplifying procedures and equipment, there is need not to assemble expensive pumps, automatic throttling pipes, downhole pressure and drilling tools and ground equipment. Automatic control system mainly using rotary control head and conventional drilling. Prepare throttle manifold, liquid gas separator, $18{ }^{\circ}$ slope drill pipe, six square drill pipe (such as the well team does not match top drive) and so on. Hydraulic calculation software through the pipe throttling control box to regulate the throttle tube. The throttle valve of the sink realizes the control of pressure drilling ${ }^{[1-5]}$. The effect of fine controlled pressure is less than conventional drilling,

make narrow-density window section and high-pressure reservoir fast drilling. This is an efficient and rapid leakage control method for well penetration ${ }^{[6-7]}$. Using the simple controlled pressure technology, Yingxi block achieved normal drilling oil timely detection and protection reservoir, reduced the lost circulation and the well control of construction risk, improve the rate of penetration.

The simple control pressure drilling technology is to use the rotary blowout preventer in the wellhead. Set up the barrier between the wellbore and the drilling platform, and return the annulus to the fluid to guide the wellbore. The coordination between the simple control pressure choke manifold in parallel with the drilling team's throttling manifold. In the wellhead, pressure is adjusted dynamically, so as to realize drilling, single root and drilling condition well. The bottom is always in the "micro-balance" state of the drilling technology. Advantages of the technology:

Drilling, connecting single root and starting up the bottom of drilling condition are all in "micro-balance". In the state, the positive pressure difference of bottom hole is relatively small, which can reduce the liquid phase of drilling fluid and solid phase intrusion. The depth of the reservoir can reduce the damage to the reservoir and timely discover and protect the oil.

Small wellbore pressure fluctuation is suitable for drilling in "narrow density window" formation. The operation can reduce or even avoid the leakage of the stratum drilling. The well control risk brought by the leakage of wellbore drilling fluid loss, it can also significantly reduce drilling costs.

Simple control pressure drilling technology is relatively conventional drilling. beneficial to reduce the "pressure holding effect", effectively avoid the rock 
repetition broken, improve drilling speed. The simple control pressure drilling technique was used to solve the chaigou formation of Yingxi block. The difficulties in conventional drilling should strengthen the formation lithology, formation pressure and formation oil.

The real-time monitoring of air and water intrusion into wellbore is convenient for the control engineer according to the actual situation. The situation regulates the wellhead backpressure, drilling fluid density and other corresponding measures.

\section{Simple control and pressure drilling technology measures and application.}

\subsection{Simple control pressure drilling technology measures.}

According to the adjacent well data, the pore pressure and leakage in the lower part of the dry chaigou formation were predicted. Under the condition that the wellbore control pressure technology is implemented, the safe drilling pressure window is clarified and the equivalent drilling of safe drilling is calculated.

\subsubsection{Drilling operation technical measures.}

Drilling fluid circulation path: drilling pump, inside of the drill pipe, the inner ring of the well, the wellhead rotary blowout preventer, the simple control pressure throttle manifold, the well team throttling manifold, the liquid gas separator, the conical tank.

Treatment of overflow: pay close attention to wellhead pressure and drilling flow. When the parameters and gas test are active, overflow is occurred and the throttle control valve is in the wellhead. Apply back pressure $2 \mathrm{MPa}$ and observe for 5 minites, if the overflow is not stopped, continue to increase the wellhead. If pressure is $0.5 \mathrm{MPa}$, encrypted sitting position observation, real-time monitoring liquid level rise until the overflow stops. If the back pressure increases to more than $5 \mathrm{MPa}$ overflow, then it needs to be adjust drilling fluid density until return to zero recovery drilling.

The treatment measures for the leakage of the well: the leakage of the well, stop drilling and keep on track. To pull the bit off the bottom of the well. If the wellhead has back pressure, reduce the wellhead pressure to $0.5 \mathrm{MPa}$ until the well leakage stops. When the wellhead has no back pressure or the wellhead return to zero, the well leakage is still do not stop reduce the drilling fluid density until recovery drilling.

\subsubsection{Technical measures for single operation.}

The controlled engineers calculate the annulus pressure value accurately according to the drilling parameters. To apply the back pressure value of the wellhead to stop the pump. Operation procedure: first, wash the well and stop the disc, then lift the drilling tool to the proper position of the elevator to stop the pump, finally stop the pump. The backpressure compensated annulus pressure is applied to the wellhead to achieve the single operation.

\subsubsection{Technical measures for drill-down operation.}

The drilling operation shall be strictly followed in accordance with the operating procedures, and the speed shall be controlled and lowered. Prevent the wellbore from producing excessive fluctuation pressure.

Drilling operation in bottom hole "balance" and the wellhead back pressure to zero as the basis, the design of heavy mud cap density and height, the drill before heavy mud cap, injected $5 \mathrm{~m}^{3}$ high viscosity fluid as smooth plug, in order to prevent the oil and gas channeling. Up drilling operations should always maintain the bottom hole pressure in a state of "balance".Be implemented in wellhead back pressure trap, trap back pressure need to supplement the drilling fluid in well operation, to supplement the drilling fluid in well operation depends on the rig drilling pump emissions reduction after processing by kill manifold injection, so the drill operation drilling fluid circulation path is: drilling pump to kill manifold, internal control line to wellhead rotating blowout preventer, simple control pressure throttle manifold to rig the throttle manifold to liquid gas separator, tapered tank.

Drilling fluid circulation path of the drilling operation: the wellhead rotary blowout preventer, the simple control pressure throttle manifold, the well team throttling manifold, the liquid gas separator, the conical tank.

\subsection{Application effect}

Simple control pressure drilling technology test with bottom hole "balance" as the core implementation of hole drilling, and tripping operation and achieve the purpose of the timely detection and reservoir protection, help to accurately evaluate and under capacity within ganchaigou formation in Yingxi block, as shown in the table 1 .

Table 1. Statistical table for the detection and protection of reservoir effect.

\begin{tabular}{c|c|l}
\hline Well & $\begin{array}{l}\text { Controlled } \\
\text { pressure } \\
\text { drilling } \\
\text { section } / \mathrm{m} .\end{array}$ & Test effect description \\
\hline $\begin{array}{c}\text { S41-6- } \\
1\end{array}$ & $3800-3920$ & $\begin{array}{l}\text { After acidification, 4 mm oil nozzle is } \\
\text { controlled and sprayed for production. } \\
\text { Industrial oil flow }\end{array}$ \\
\hline S208 & $3700-3868$ & $\begin{array}{l}\text { Put the tubing into production directly. } \\
\text { Liquid mixture 78. 83 } \mathrm{m}^{3}\end{array}$ \\
\hline S3-2 & $2638-3250$ & $\begin{array}{l}\text { During the construction period, three } \\
\text { times of overflow, after effect gas } \\
\text { detection of total hydrocarbon. Up to } \\
34 \%\end{array}$ \\
\hline S3- & $2520-3359$ & $\begin{array}{l}\text { Drilling oil and gas show active, well } \\
\text { depth 2 856 2661m The total } \\
\text { hydrocarbon of 2661 m was up to 75\%. }\end{array}$ \\
\hline S51 & $3800-4800$ & $\begin{array}{l}\text { Test for production, gush crude oil 14 } \\
\mathrm{m}^{3} .\end{array}$ \\
\hline S52 & $4200-4407$ & $\begin{array}{l}\text { Original drilling rig test oil, nissan oil 67. } \\
62 \mathrm{~m}^{3}, \text { Nissan 8337 } \mathrm{m}^{3}\end{array}$ \\
\hline
\end{tabular}


The average single well leakage drilling fluid in the test well of simple controlled pressure drilling $56.12 \mathrm{~m}^{3}$.the conventional drilling average single well leakage drilling fluid $109.80 \mathrm{~m}^{3}$. It is obvious that the pressure drilling technology reduces or avoids the well leakage, and does not occur in a controlled risk event caused by leakage, overflow or leakage transfer, which effectively guarantees the safety of drilling. Comparison of the leakage of drilling fluid in conventional well and simple controlled pressure test. See table2.

Table 2.simple control test well and conventional well in 2016 comparison table of leakage in the dry chaigou formation.

\begin{tabular}{|c|c|c|}
\hline $\begin{array}{c}\text { Technology } \\
\text { tegory }\end{array}$ & Well & $\begin{array}{l}\text { Loss of drilling } \\
\text { fluid } / \mathrm{m}^{3} \text {. }\end{array}$ \\
\hline $\begin{array}{l}\text { Simple control } \\
\text { pressure }\end{array}$ & $\begin{array}{c}\text { S41-6-1 } \\
\text { S3 }-2 \\
\text { S3-2X1 } \\
\text { S1 }-3 \text { X1 } \\
\text { S208 } \\
\text { S52 } \\
\text { S51 }\end{array}$ & $\begin{array}{c}1.2 \\
315.94 \\
48.0 \\
27.71 \\
0 \\
0 \\
0\end{array}$ \\
\hline \multicolumn{2}{|c|}{$\begin{array}{c}\text { The average single well leakage } \\
\text { loss of simple controlled pressure } \\
\text { drilling. }\end{array}$} & 56.12 \\
\hline $\begin{array}{l}\text { Conventional } \\
\text { drilling }\end{array}$ & $\begin{array}{c}\text { S49 } \\
\text { S205 } \\
\text { S48 } \\
\text { S206 } \\
\text { S207 } \\
\text { S38-4-1 }\end{array}$ & $\begin{array}{c}30 \\
56.70 \\
30.47 \\
22.0 \\
309.1 \\
210.55\end{array}$ \\
\hline \multicolumn{2}{|c|}{$\begin{array}{l}\text { Average single well leakage loss } \\
\text { of Conventional controlled } \\
\text { pressure drilling. }\end{array}$} & 109.8 \\
\hline
\end{tabular}

Statistical analysis after completion of simple controlled pressure test well, average completion period 89 days, non-production time $7.77 \%$, average single well plugging loss time 74 houres.The average completion period of conventional drilling in 2015 was 104 days, non-production time $20.41 \%$, the average single-well loss time was 362 houres. In 2015 the simple control pressure test well is smaller than the conventional drilling completion cycle short 14days, non-production time decreased by $12.64 \%$, when the average single well is blocked, it goes down by $79.70 \%$.Simple control pressure drilling technology can reduce or avoid leakage. In addition, the complex processing time of wellbore is greatly reduced, and the production time of drilling operation is obvious.

\section{Cognition and suggestion.}

The result of the simple controlled pressure drilling technique is analyzed. The technology is suitable for the reservoir of "narrow density window" in dry chaigou formation in Yingxi block. Drilling can reduce or even avoid loss of drilling fluid, timely detection and protection. The purpose of the oil and gas layer is to increase the speed of the machine and reduce the nonproduction time.
Because the simple control pressure drilling equipment is different from the conventional drilling equipment. In the process, there is no connection between the equipment, and it is suggested to increase the conventional equipment. The simple control and pressure drilling equipment has been improved to make the simple control drilling technology early.

Simple control pressure drilling technology is less configuration, low input and simplified. Under the condition of operation, fully exert control equipment and field well control equipment. To prevent a large amount of fluid from entering the wellbore or leaking into the stratum. To control pressure drop dense, safe speed up the purpose, in high pressure, low permeability block. Or narrow density window section has extensive application value.

\section{References}

1. SHI Lin, YANG Xiongwen, ZHOU Yingcao, et al. Domestic fine controlled pressure drilling equipment inthe Tarim Basin using[J].Natural gas industry, 2012, $32(8): 6-10$.

2. WANG Qian, WEI Haitao, ZHOU Yingcao, et al.Thescreening and evaluation method for the pressure controldrilling technology[J].Petroleum Machinery, 2011, 39 (12) : 9-13.

3. YI Ming, CHEN Ruoming, YANG Gang. Research on pressure control drilling technolog[J]. Xinjiang Oil andGas, 2010, 6 (4) : 32-37.

4. ZHOU Jian, JIA Hongjun, LIU Yongwang, et al. Research on safe drilling technology for ultra deepultrahigh pressure saltwater zones in piedmont area, Kuche[J]. Drilling Fluid \& Completion Fluid, 2017, 34 (1) : 54-59.

5. LIU Xiaolan, YU Li song. Determination of formation collapse pressure of Bo nan shale taking into account triaxialstresses[J]. Drilling Fluid \& Completion Fluid, 2016, 33 (4) : 27-31.

6. SUN Kai, LIANG Haibo, LI Qian, et al. Research onmud cap design managed pressure drilling $[\mathrm{J}]$. Petroleum Drilling Techniques, 2011, 39 (1): 36-39.

7. GUO Jigang. Application of precise dynamic pressurecontrol well cementing technology in block Shunnan[J]. Drilling Fluid \& Completion Fluid, 2016, 33 (5) : 76-79.ese) 